\title{
Revisit of Lessons Learned: Evolution of the Aerospace Engineering Summer Camp in Year Three
}

\section{Dr. Kristi J. Shryock, Texas A\&M University}

Dr. Kristi J. Shryock is an Instructional Associate Professor in the Department of Aerospace Engineering and Senior Director of Retention in the Look College of Engineering at Texas A\&M University. She received her BS, MS, and $\mathrm{PhD}$ from the College of Engineering at Texas A\&M. Kristi works to improve the undergraduate engineering experience through evaluating preparation in mathematics and physics, incorporating non-traditional teaching methods into the classroom, and engaging her students with interactive methods.

\section{Mr. David B Kanipe, Texas A\&M University}

After receiving a BS in Aerospace Engineering in May 1970, followed by a MS in Aerospace Engineering in August 1971 from Texas A\&M University, Mr. Kanipe accepted a position with NASA at the Manned Spacecraft Center in Houston and began his professional career in November 1972. A month after his arrival at NASA, the last Apollo mission, Apollo 17, was launched. Obviously, that was exciting, but in terms of his career, the commencement of the Space Shuttle Program in November 1972 was to have far more impact. As a result, David was able to begin his career working on what he says was the most interesting and exciting project he could possibly imagine: the Space Shuttle. Over his career, David held successively influential management positions including Deputy Branch Chief of the Aerodynamics Branch in the Aeroscience and Flight Mechanics Division, Chief of the GN\&C Analysis and Design Branch, Deputy Chief of the Aeroscience and Flight Mechanics Division, and for the final 10 years of his career, Chief of the Aeroscience and Flight Mechanics Division in the Engineering Directorate at the Johnson Space Center. Dave retired from NASA at the end of 2010 after more than 38 years of service in the US Space Program. His career spanned numerous projects and programs, including both crewed and robotic spacecraft. After retiring from NASA, the Head of the Aerospace Engineering Department at Texas A\&M University asked him to come to A\&M as a Senior Lecturer to teach a Senior Capstone Design course focusing on Spacecraft Design. In September 2014 he became an Associate Professor of Practice in the Aerospace Engineering Department at Texas A\&M. He began his fourth year of teaching at Texas A\&M in September 2014. 


\title{
Revisit of Lessons Learned: Evolution of the Aerospace Engineering Summer Camp in Year Three
}

\begin{abstract}
Three years ago, Texas A\&M University held a summer camp to improve outreach to high schools and encourage interest in aerospace engineering. A critical evaluation three years later evaluates the successes and revisions by the department. In an effort to improve the student experience, each subsequent camp reflects on lessons learned from previous camps, and the latest camp is no different.

In early years, additions included having practicing engineers participate in camp and integrating different design tracks using a systems approach. In the most recent version of the camp, the structure was modified significantly to accommodate additional students and provide an additional field of interest. In addition to the previous aircraft and rocket tracks, a third track, called Air Ships, focused on the use of electronic control systems to maneuver the lighter-thanair swimmers. Adding a new track allowed an increase in the number of students attending camp from 30 to 60 with the team size in each track increasing from 15 to 20 students. Another innovation for the third camp was the inclusion of interested high school science and mathematics teachers in the camp. In an effort to educate one and reach a hundred, the camp provided four teachers with inspiration and ideas that could be transplanted to their high school classrooms.
\end{abstract}

\section{Introduction}

The paper will present modifications to the camp structure, results from assessment of the camp, lessons learned by the instructors, comments from both students in the camp and personnel involved, and future plans based on evaluations from the current year. In summary, outcomes have been achieved, and the majority of students felt their experiences were particularly rewarding. The intent is for this review to provide guidance and inspiration to other aerospace engineering programs seeking to engage high school students into their program of study.

\section{Camp Selection and Structure}

The aerospace engineering (AE) camp, Camp SOAR (Summer Opportunities in Aerospace Research), provided an opportunity for students entering their junior and senior year of high school to explore the major and learn more about AE at Texas A\&M University (TAMU). From the first year, it was understood the process used to select the camp participants was of fundamental importance to the success of the camp, and nothing about the student application process had changed in the three years of camp ${ }^{1}$. Student application packages for Camp SOAR 
consisted of the following: 1) high school transcript, 2) teacher recommendation, 3) honors and activities, 4) essay 1, and 5) essay 2. Applicants were evaluated only on the basis of the information contained in the application. Aspects, such as gender, race, and ethnicity, were not considered during the evaluation of the application. In the first essay, students were asked to explain their interest in $\mathrm{AE}$, and the second essay asked for a description of the biggest obstacle in life and how it had been overcome. The use of a selection protocol as well as an impartial review process provided a straightforward means of attaining the objective of impartial selection for camp participants.

Each year of camp followed the same schedule. Camp SOAR began on Sunday afternoon with a welcome lunch for participants and family members and concluded on Friday afternoon. Each day was organized a little differently but typically involved facility tours and a limited amount of instruction with the majority of the day spent with hands-on activities. It was important to continually be conscious of the fact that the participants were high school students (including juniors) who could possibly be easily overwhelmed. Concluding activities on Friday, which are always popular included design project demonstrations by the students for family members.

One aspect that changed from the first year was the number of participants. In the first two years, 30 high school students participated in Camp SOAR each year. With two project tracks, teams were evenly split with 15 students each. In the third year of the program, the goal was to increase the number of participants without sacrificing the small faculty-to-student ratio achieved in the first two years. Faculty members who had been teaching the Aircraft and Rocket design tracks for the first two years felt that 20 students per track (as opposed to 15) would be manageable and still provide comparable hands-on time. Therefore, a third track of 20 students was offered for a total of 60 student participants during the third year (2014).

\section{Project Track Changes}

To accommodate the increase in number of students participating, a third project track designed for 20 students was offered during the third year, summer 2014, called Air Ships. The Air Ship group utilized the Air Swimmers toy ${ }^{2}$ filled with Helium to provide buoyancy.. A flappable tail provided the propulsion for the air swimmer and a movable weight provided pitch control. A more detailed description of the Air Swimmer Track will be provided subsequently.

As mentioned above, both the Aircraft and Rocket tracks were increased from 15 to 20 students each in order to bring the overall camp size to 60 students. Initially, there was some concern regarding a $30 \%$ increase in class size; but in practice the effect was negligible. The benefit of being able to reach larger numbers of interested students throughout the country more than made up for the small increase in the logistical burden and the cost of additional materials and counselors. 
In addition to adding a track and increasing the number of students attending Camp SOAR, minor changes were made to the structure of the Aircraft and Rocket hands-on projects. These changes were made in response to issues encountered during the 2013 camp. In an effort to encourage the students to begin thinking in terms of the "System", the final 2013 camp project was designed to have the Rocket and Aircraft teams design and build a vehicle that would launch with a glider on its back (a la the Space Shuttle) and then release the glider to fly back to the ground. In model rocket parlance these are called "boost gliders". The project was structured to require the two tracks to form new teams consisting of Rocket track members to build the rocket and Aircraft track members to design and build the glider. The teams would then compete on the basis of maximum time aloft. The task required that the Rocket students build a rocket that would launch the system as high as possible, considering the rocket motor constraints. The Aircraft team was required to design a glider that, once free of the rocket, would remain in the air as long as possible. The longest flight time, from launch to glider landing, would be the winner. While the rocket and the glider were designed and built separately, the design and placement of the mechanism that held the glider on the back of the rocket was to be a team effort. It should be noted that in the 2013 camp, the rocket was powered by a solid propellant motor, such as those used in Estes brand model rockets. The actual details of the problems encountered in the 2013 camp are irrelevant to the current discussion. Suffice to say that they were serious enough to lead to $0 \%$ mission success on fly-off day.

This experience led to two changes to the Camp SOAR 2014: 1) compressed-air rockets would be used instead of solid motor Estes type rockets and 2) the rocket and glider construction was standardized to ensure successful performance. While these changes had the desired effect of producing successful flights, they also resulted in over simplifying a project that was originally meant to challenge the students.

\section{Project Details}

As previously mentioned, the 2014 edition of Camp SOAR consisted of three project tracks: Aircraft, Rockets, and Air Ships with the Air Ships, which was new for 2014.

The teams in the Air Ship group utilized the popular Air Swimmers toy ${ }^{2}$, a lightweight nylon bladder about four feet long, shaped and colored like a fish and filled with approximately 4.5 cubic feet of Helium to make it buoyant. Each of these floating vehicles was outfitted with flapable tail for propulsion (powered by a small DC motor) and a pitch control device consisting of a weight that a second small DC motor moves along a track to control pitch. The tasks for the students were twofold:

1) Experiment with different tail shapes to determine the one with best performance. Toward this end, the students cut tails out of thin plastic and glued them over thin carbon rods,

2) Modify the Air Swimmer by adding an Arduino microcontroller connected to the tail motor to allow for autonomous flight of the Air Swimmer. 
Additional required materials included a disposable A23 12V battery and an H-bridge Controller Board kit for Arduino. The Arduino was programmed using an in-house developed computer code that allowed the students to adjust the amplitude and frequency of the tail flapping. The objective was to determine the design parameters that permitted the fastest completion of a given course. Flight demonstrations of the Air Ship are shown in Figure 1 and Figure 2.

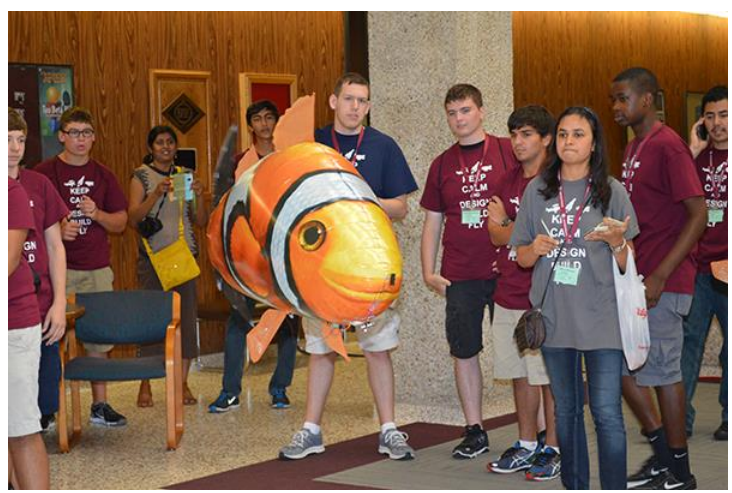

Figure 1. The Air Swimmer.

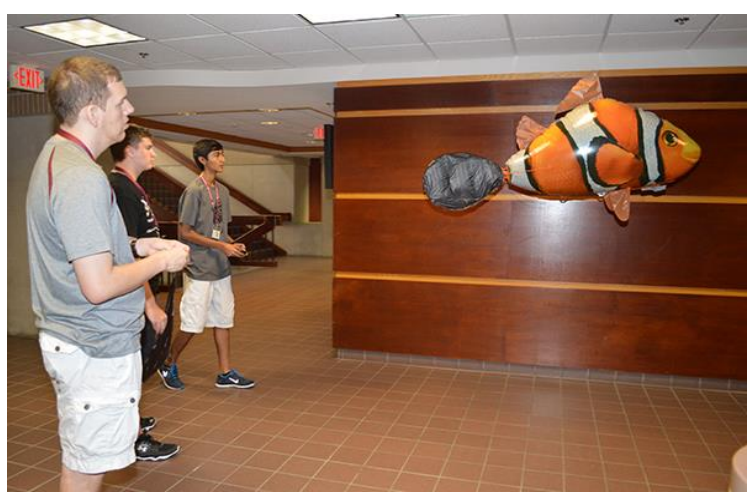

Figure 2. Flying the Air Ship.

During the third year of Camp SOAR, projects utilized in the Aircraft and Rocket tracks were essentially unchanged from the previous year. Each began with simple projects intended to illustrate the physics involved in aircraft and rocket flight. Paper airplanes were utilized to demonstrate the basic influences on control, stability, and trim. Figure 3 and Figure 4 show students constructing and testing their paper airplane.

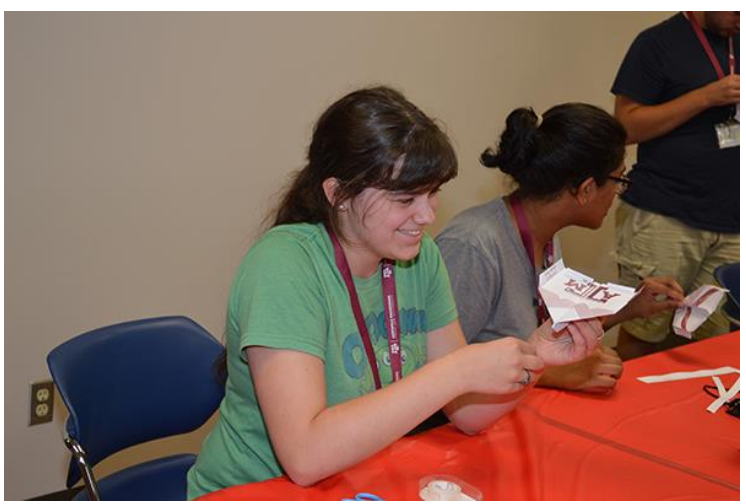

Figure 3. Paper airplane construction.

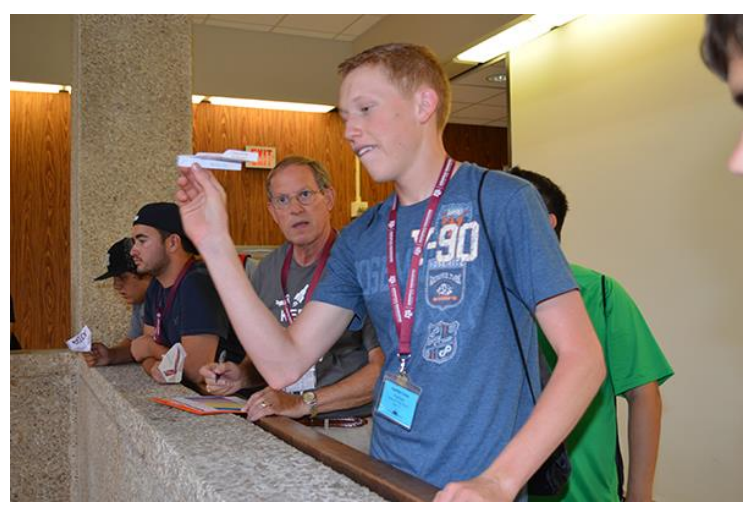

Figure 4. Test gliding.

The fundamentals of rockets were demonstrated through the use of a compressed-air-rocket system $^{3}$. The rockets were assembled using thin-walled cardboard tubes about 11 inches long and plastic parts printed using a 3D printer, specifically a MakerBot Replicator 2X and Replicator 2. The resulting rockets were then launched using a compressed air launch system ${ }^{1}$ to illustrate ballistic trajectories, the effects of drag, and the factors affecting stability. The compressed-air-system shown in Figure $5 \mathrm{a}$ and $5 \mathrm{~b}$ was capable of sending a $30 \mathrm{~g}$ rocket almost 400 feet. 


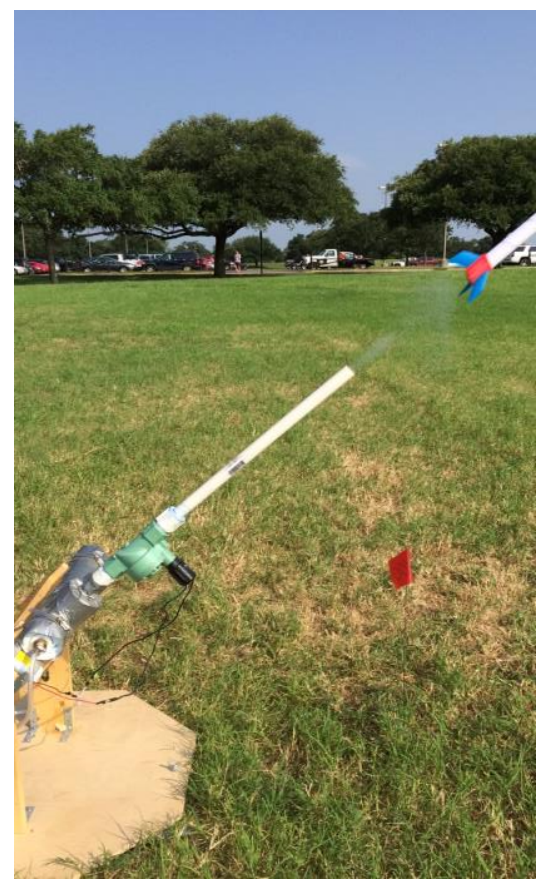

Figure 5a. Launcher in action

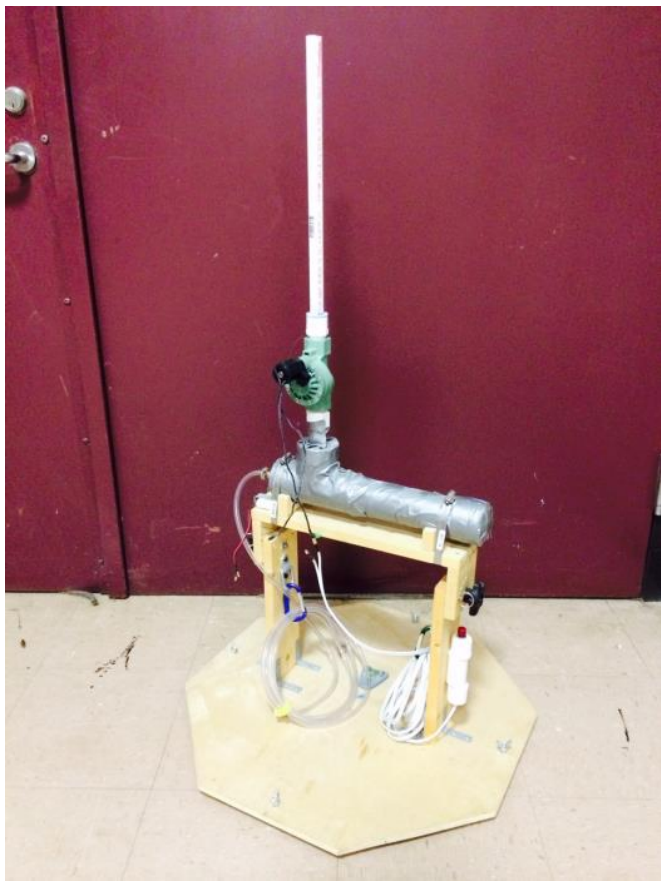

Figure 5b. Launcher

One of the streamlining techniques employed during Camp SOAR in summer 2014 was to use $3 \mathrm{D}$ printers to produce the nose cones and fins for the rockets. While the use of 3D printers was useful when so much activity was compressed into a relatively short time frame, it was concluded that it may hinder creativity if not utilized carefully. The feeling for future iterations was that 3D printing should be utilized, but only if the creative aspect can be preserved. Figure 6 and Figure 7 showcase the colored parts of the rockets.

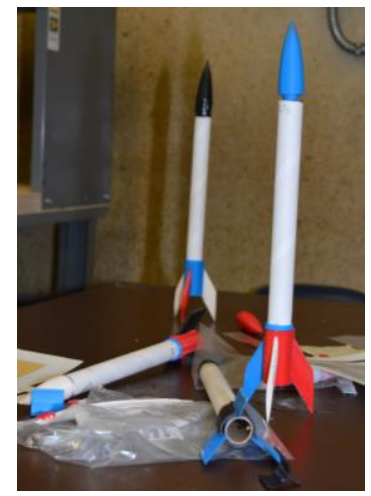

Figure 6. Student-built paper rockets

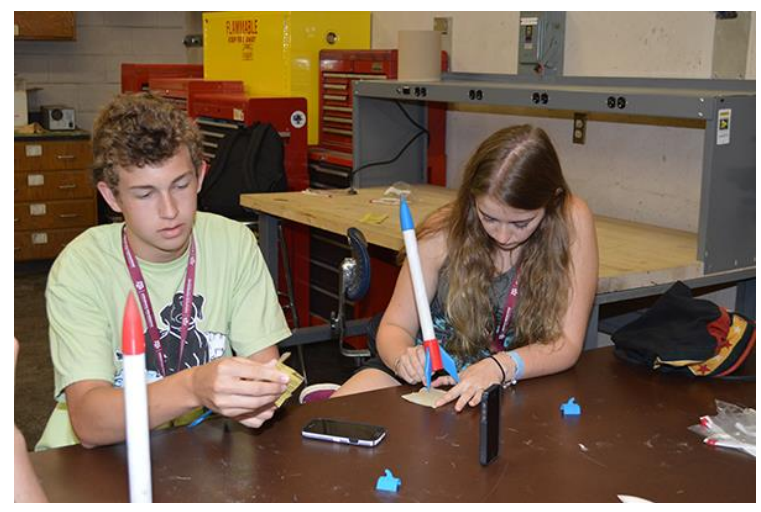

Figure 7. Students fine tuning their rockets.

Two of the students' favorite competitions with respect to the Rocket track were held during this phase of the camp: 1) longest down-range distance and 2) the most accurate down-range 
location. The longest down-range distance is a straightforward competition that rewards the students who build their rockets more carefully and have the lowest mass, as show in Figure 8. The objective of the most accurate down-range location competition is to land as close as possible to a flag placed at a given location on the field. For example, the rocket must land as close as possible to a flag 197 feet from the launch point. The graphic in Figure 9, based on analysis and test data, was produced to aid the students in choosing the chamber pressure $\left(\mathrm{P}_{\mathrm{c}}\right)$ and launch angle $(\theta)$ required to send their rocket (of mass $m$ ) to the flag. Each student had two opportunities to get close to the flag. After the first round the average distance to the flag was about 20 feet. After the second round, however, when the students were able to take advantage of the first round knowledge, the error dropped to an average of 10 feet. The compressed air system was very suitable for this as it was very reliable and able to be cycled quickly. Being mostly ballistic can be seen as a drawback, but it created a good opportunity to explain the difference between ballistic and powered rockets.

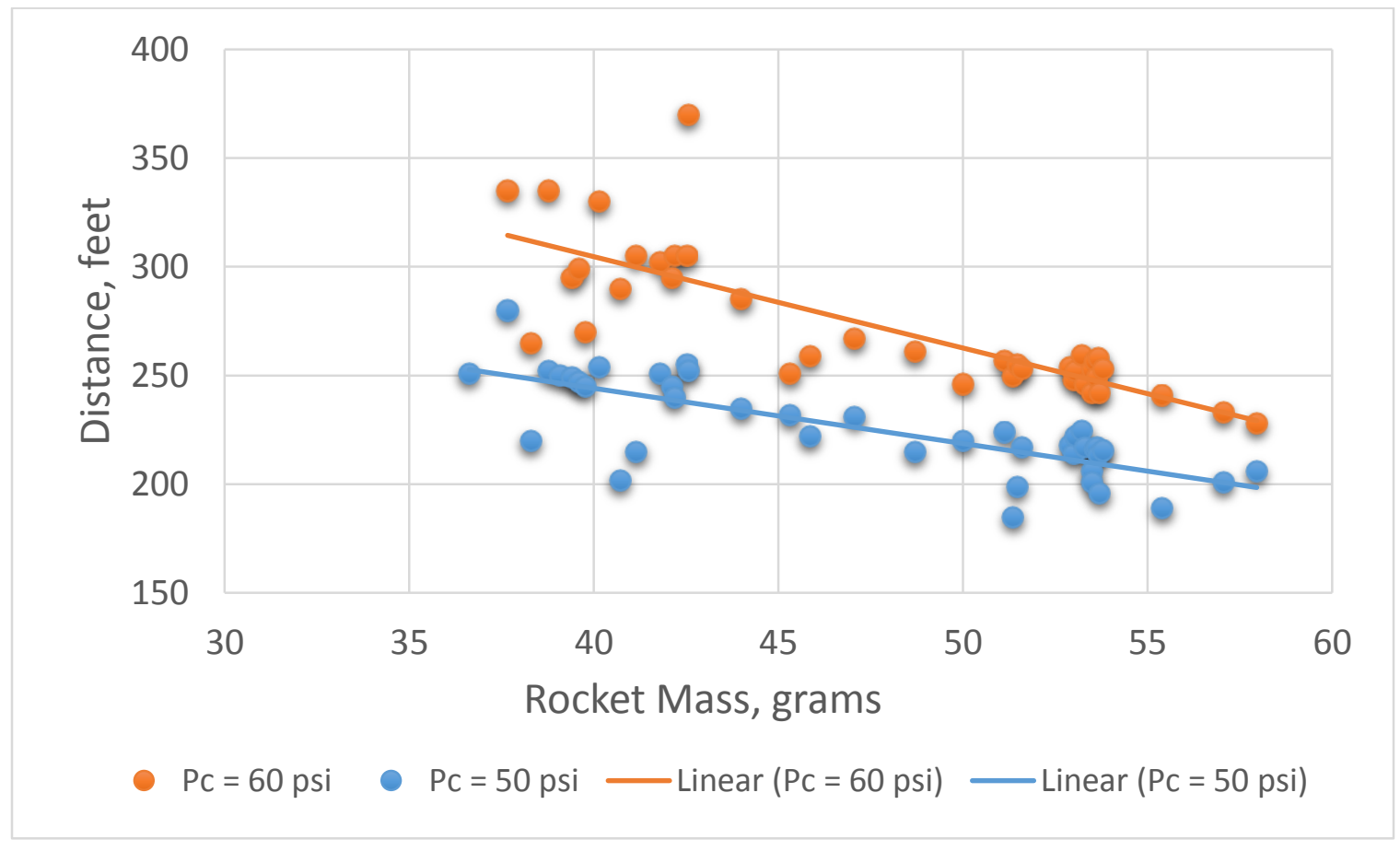

Figure 8. Down-range distance as a function of paper-rocket mass. 


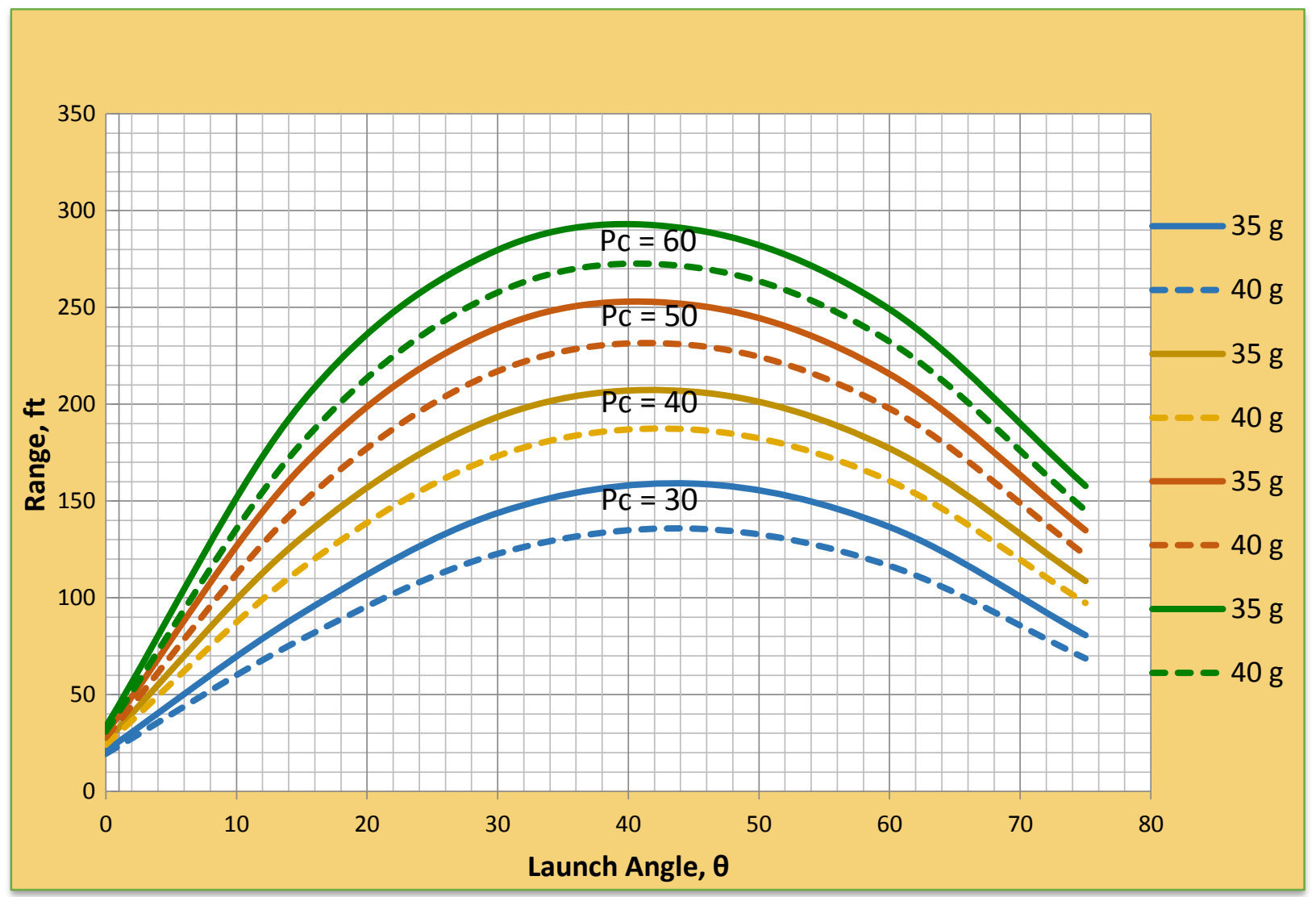

Figure 9. Range as a function of launch angle, mass, and $\mathrm{P}_{\mathrm{c}}$.

As mentioned earlier, the 2013 version of this project did not live up to expectations. In the 2014 camp, the compressed-air-rocket used instead of the solid-propellant rockets, and the hook/release interface between the rocket and the glider was identical for all teams and well proven before the camp began. The same competition that failed in the 2013 camp was conducted successfully in 2014 due to changes specifically designed to increase the probability of some level of success for all teams.

As in 2013, the students were organized in teams consisting of a rocket students and aircraft students. The rocket was designed to be stable and lift the glider as high as possible, while the glider had to be designed for stable flight and trimmed to fly smoothly for as long as possible. This was the final project of the camp, and the competition was held on the morning of the last day of camp in a large field on the campus. The rocket/glider combination worked exceptionally well this time, and the fly-off was successful, although the flight times were somewhat disappointing. The fly-off results are shown in Table 1. Improvements in the glider design-andbuild process are already in work to increase glider performance in 2015 without sacrificing the camper's ability to be creative. 
Table 1. TAMU Camp SOAR Airplane and rocket flight test activity 2014.

\begin{tabular}{|c|c|c|c|c|c|c|}
\hline \multicolumn{7}{|c|}{ Score Sheet } \\
\hline & & $\begin{array}{c}\text { PERFORM } \\
\text { ANCE }\end{array}$ & TEAMWORK & SCORES & $\begin{array}{l}\text { RANK } \\
\text { ORDER }\end{array}$ & RESULTS \\
\hline & & C & d & $c+d$ & & \\
\hline & & $\begin{array}{c}\text { Total } \\
\text { Time } \\
\text { Aloft } \\
\text { (Seconds) }\end{array}$ & $\begin{array}{l}\text { Safe Ops } \\
\text { and Meets } \\
\text { Mission } \\
\text { Objectives } \\
\text { (Score } 1 \text { to } \\
5 \text { ) }\end{array}$ & $\begin{array}{c}\text { Performance } \\
+ \\
\text { Teamwork }\end{array}$ & & $\begin{array}{c}\text { Top Three } \\
\text { Teams }\end{array}$ \\
\hline 1 & ALPHA & 9.0 & 5 & 14 & 12 & \\
\hline 2 & BRAVO & 7.8 & 5 & 12.8 & 17 & \\
\hline 3 & CHARLIE & 32.9 & 4 & 36.9 & 2 & $<$ Second \\
\hline 4 & DELTA & 6.2 & 5 & 11.2 & 20 & \\
\hline 5 & ECHO & 9.4 & 5 & 13.4 & 15 & \\
\hline 6 & FOX & 13.7 & 4 & 17.4 & 6 & \\
\hline 7 & GOLF & 8.8 & 5 & 13.8 & 13 & \\
\hline 8 & HOTEL & 8.4 & 4 & 12.4 & 18 & \\
\hline 9 & INDIA & 9.3 & 5 & 14.3 & 11 & \\
\hline 10 & JUDY & 17.4 & 4 & 21.4 & 4 & \\
\hline 11 & KILO & 35.2 & 5 & 40.2 & 1 & $<$ First \\
\hline 12 & LIMA & 7.2 & 5 & 12.2 & 19 & \\
\hline 13 & MIKE & 10.7 & 5 & 15.7 & 9 & \\
\hline 14 & NOVEMBER & 11.2 & 5 & 16.2 & 8 & \\
\hline 15 & OSCAR & 15.2 & 4 & 19.2 & 5 & \\
\hline 16 & PAPA & 12.0 & 5 & 17 & 7 & \\
\hline 17 & QUEBEC & 8.5 & 5 & 13.5 & 14 & \\
\hline 18 & ROMEO & 10.5 & 4 & 14.5 & 10 & \\
\hline 19 & SIERRA & 8.0 & 5 & 13 & 16 & \\
\hline 20 & TANGO & 23.5 & 5 & 28.5 & 3 & $<$ Third \\
\hline
\end{tabular}

\section{Project Lessons Learned}

Camp SOAR held in the summer of 2014 was the third offering by the AE department at TAMU. All hands-on projects used in Camp SOAR are carefully designed to be challenging, but also to fall within definite levels of difficulty. However, the projects typically required an increased skill level as the week unfolded. Attendees have consistently provided feedback on the satisfaction of being challenged. Unfortunately, an overreaction to the issues of the 2013 camp led to the development of a 2014 camp structure that turned out to be more pre-determined and 
restrictive than anticipated, ultimately limiting the opportunities for creativity on the part of the students. The Aircraft and Rocket tracks were standardized, such that the rockets and the gliders were a set of pieces to be glued together. There was no freedom to create a unique model. That was a mistake, and it will not be repeated in the future. Above all else, the projects must not only be challenging, but encourage creative expression.

\section{Additional Enhancement of Camp SOAR 2014}

In addition to using Camp SOAR as an outreach tool for students, the desire was to also encourage and provide ideas for high school science teachers. In an effort to teach one and reach hundreds, four high school science teachers were invited to attend the 2014 camp to observe, take part in the activities, and provide comments following the camp. By all indications, the teachers thoroughly enjoyed their time at the camp and went home with new ideas and renewed enthusiasm. This program will continue to be developed and expanded in the next offering of the camp.

Another augmentation to the 2014 camp was the incorporation of practicing engineers from industry during one attending the camp during summer 2013 and two attending in summer 2014. The engineers spent the week observing, mentoring, and providing feedback to the camp participants. Students remarked on their appreciation of learning of the real-world application of their projects through their discussion with the engineers. While the benefit of industry representatives meeting potential future hires before the students even begin college was known to be a benefit, there was another unintended advantage for industry representatives: they truly relished the opportunity to meet the camp counselors, who are current undergraduate students in the AE program, and perhaps future hires. They have also enjoyed their extended interactions with these students. This slightly more personal relationship allowed them to evaluate the counselors in leadership situations as well as the occasional difficult situation. The process of incorporating engineers will continue in the next year's camp.

\section{Assessment and Evaluation}

To aid in the evaluation of Camp SOAR, participants completed surveys, which rated various aspects of the camp and allowed for suggestions to be provided. Overwhelmingly, the responses from students regarding their camp experience have been positive. Information is collected in pre- and post-survey formats containing closed-ended and open-ended questions. Feedback is received from all personnel associated with camp, including camp counselors, faculty, engineers, and high school teachers. Figure 11 displays a summary of results obtained from students in the three camps regarding the impact of Camp SOAR on their excitement for AE. 


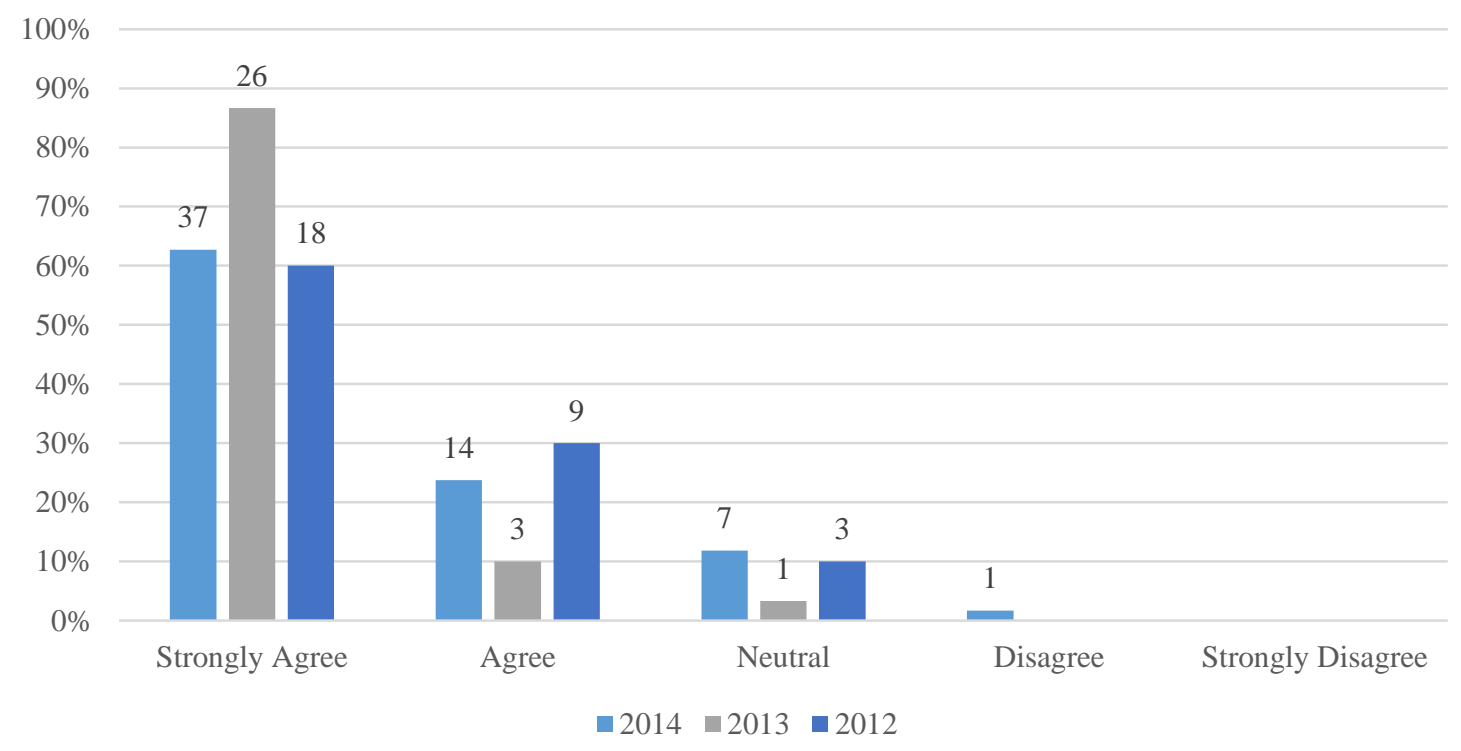

Figure 11. Participating in Camp SOAR has excited me about aerospace engineering (Q3).

Camp personnel consider feedback received when making future plans for the program. One prime example concerned feedback received from the high school teachers during the summer 2014 camp. The third track, Air Ships, was supposed to be led by one of the professors in the AE department, but due to travel requirements, the professor was replaced by two graduate students. Meanwhile, as in previous years, the Aircraft and Rocket tracks were directed by the faculty members who had done it for the previous years. In Camp SOAR 2014, however, the visiting high school science teachers took part in, or observed, all team instruction, testing, and classes. Based on their observations, they noted what they termed "a distinct increase in the energy level" in the Air Ship group when compared to the Aircraft and Rocket groups. While the professor's age is not typically an issue in a university classroom, perhaps it can be a distraction to 17 and 18 year old high school students. (Of course, it is possible that the more mature professors were uncommonly dull) but the visiting teachers suggested that it was more likely that the high school students were more comfortable with the graduate students who were significantly closer to their age. To test this theory, the 2015 camp will team graduate students with faculty members to see if there is a marked difference.

\section{Impact}

After three years, the AE department at TAMU has seen 120 potential applicants progress through the program. With 20 of the students participating in summer 2014 just entering their junior year in high school, only 100 of the total number of participants have currently been able to apply. The remaining 20 participants will be eligible to apply for fall 2016 admission. Of the 100 potential applicants, 83 students have applied to Texas A\&M. Figure 12 depicts the breakdown of majors where students applied. As shown, over $90 \%$ of students applied to 
engineering. The category STEM - non-ENGR simply means a student applied to a major in science, technology, engineering, or mathematics (STEM) other than engineering.

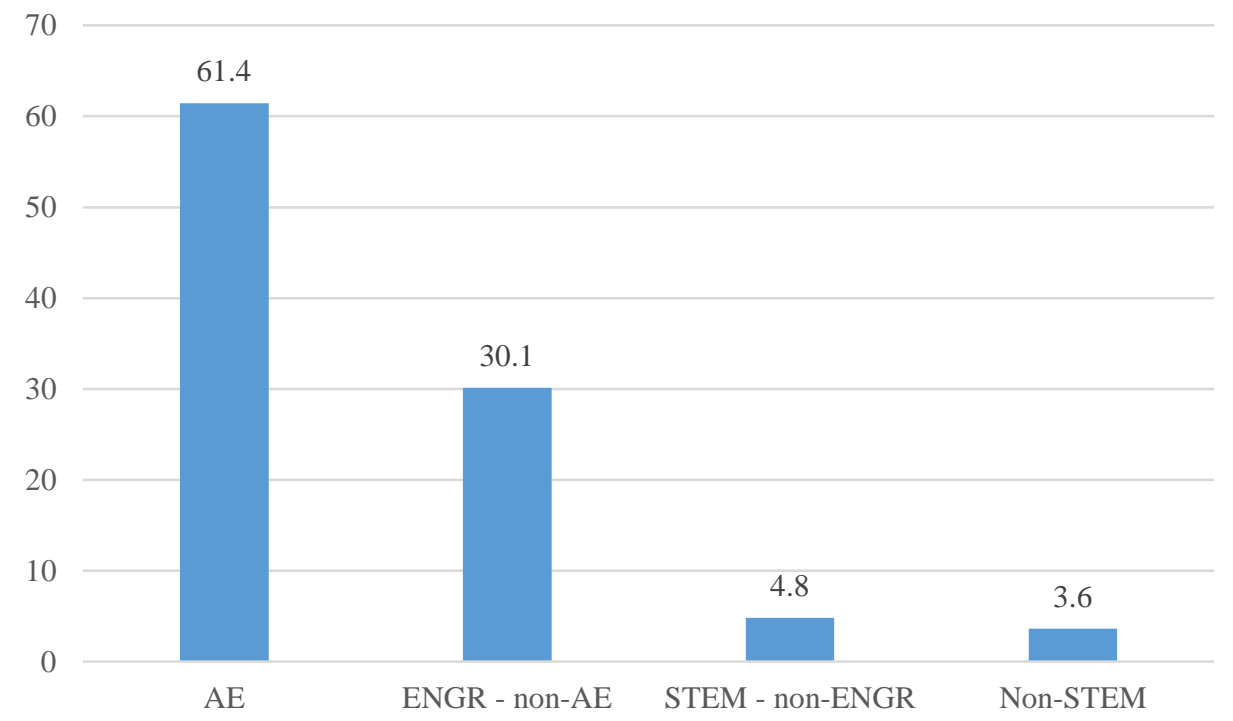

Figure 12. Analysis of majors applied at University by percentages. $n=83$

The population of 83 students includes 26 students who are currently going through the application process for fall 2015 admission. With the first camp being offered in summer 2012, the department has two complete cohorts that it has tracked: fall 2013 enrolls and fall 2014 enrolls. Once classes begin in fall 2015, the third cohort can then be officially tracked. Data is preliminary at this time due to timing. It is worth noting that one of the counselors in the 2014 Camp had attended the 2012 Camp.

From the first two cohorts, the numbers look promising. The percentage of students who have applied and been accepted by University is $81.5 \%(\mathrm{n}=54)$. The percent yield of this population is 70.5. A typical yield for engineering at University is closer to $58 \%$, so this is seen as positive. First year retention can be tracked for students from the first camp as they have completed their first year of college. Of the 12 students who entered engineering as freshmen, ten were retained in engineering after the first year, $(83.3 \%)$. This number is only slightly above the first year retention rate for all engineering students at TAMU. While the sample size is growing in terms of potential applicants, the AE department is only beginning to see matriculation of students due to the time lag between attending camp and entering college. Sample sizes are too small at this point to make valid hypotheses. Data will continue to be collected, assessed, and evaluated.

\section{Camp SOAR Philosophy}

There are three fundamental objectives driving the operation of Camp SOAR. First, Camp SOAR is a powerful recruitment tool for the AE department at TAMU. As shown in Figure 12, 
following each camp a significant percentage of the attendees have applied for admission to the TAMU and selected to major in AE. Second, since the camp attendance is limited, the competitive application process makes it possible to select the most gifted applicants from across the United States (see Figure 13). While the current number of students enrolled in the AE department from out of state is less than $7 \%$ on average, the number of out of state participants attending Camp SOAR (and many of them applying to TAMU) is $21 \%$ ! This is important since, as stated above, a significant number of these students will very likely apply for admission to the University and choose to major in AE.

Finally, substantial effort is devoted to the design of the hands-on projects in order to make them instructive, challenging, and enjoyable. When changes are made that do not work or have adverse effects, they are altered (or eliminated) as soon as possible based on feedback from camp participants. The changes reported herein will be applied to the 2015 edition of Camp SOAR.

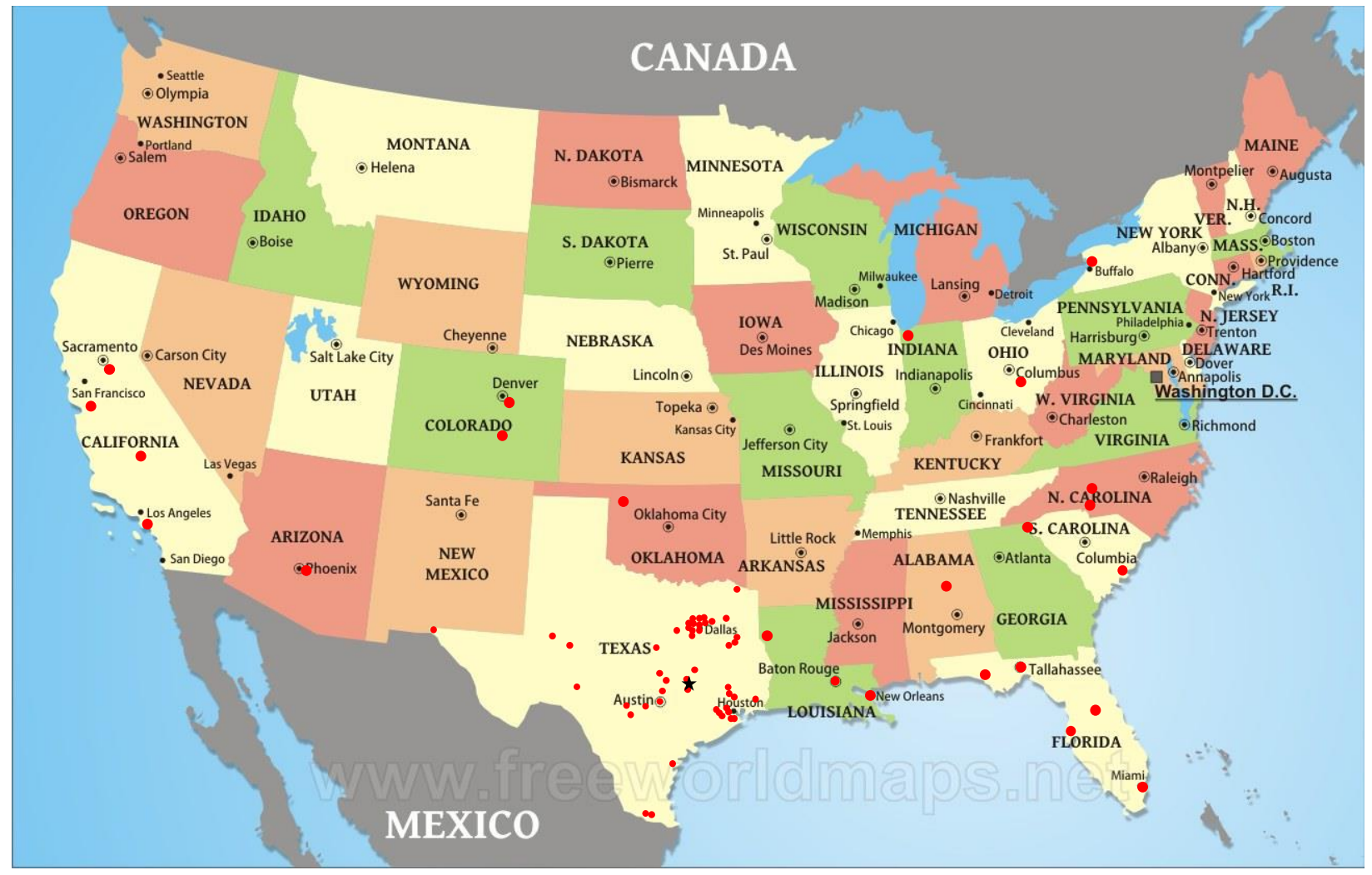

Figure 13. Location of participants (Red dots indicate hometown of participant. States include AL, AZ, CA, CO, FL, GA, IN, LA, NC, NY, OH, SC, and TX.)

\section{Conclusions}

Both the AE department and college of engineering at TAMU have directly benefitted from Camp SOAR. Feedback from students has shown repeatedly that the experience students receive 
from their camp experience is a direct reflection on their interest in attending TAMU. Growing pains related to scalability of efforts continue but are being managed. For summer 2015, 80 total students will be accepted for the program through the addition of a fourth track still to be determined. The next edition of Camp SOAR will incorporate the lessons learned from the previous three years and will provide new lessons and more metrics to use as guidance for future camps.

\section{Bibliographic Information}

1. Kanipe, D.B., Shryock, K.J., and Richard, J.C. (2013). Lessons learned by the aerospace engineering department at Texas A\&M University following its first summer camp for high school students. 2013 ASEE Conference Proceedings.

2. Air Swimmers, WMC Toys, William Mark Corporation, Claremont, CA.

3. Compressed Air Rocket, Rick Schertle, http://makezine.com/2008/12/13/compressed-air-rocket/ 